University of Nebraska - Lincoln

DigitalCommons@University of Nebraska - Lincoln

\title{
Canopy spectral invariants, Part 2: Application to classification of forest types from hyperspectral data
}

\author{
M.A. Schull \\ Boston University, schull@bu.edu \\ Y. Knyazikhin \\ Boston University \\ L. Xu \\ Boston University \\ A. Samanta \\ Boston University \\ P.L. Carmona \\ Universitat Jaumel \\ See next page for additional authors
}

Follow this and additional works at: https://digitalcommons.unl.edu/nasapub

Part of the Physical Sciences and Mathematics Commons

Schull, M.A.; Knyazikhin, Y.; Xu, L.; Samanta, A.; Carmona, P.L.; Lepine, L.; Jenkins, J.P.; Ganguly, S.; and Myneni, R.B., "Canopy spectral invariants, Part 2: Application to classification of forest types from hyperspectral data" (2011). NASA Publications. 88.

https://digitalcommons.unl.edu/nasapub/88

This Article is brought to you for free and open access by the National Aeronautics and Space Administration at DigitalCommons@University of Nebraska - Lincoln. It has been accepted for inclusion in NASA Publications by an authorized administrator of DigitalCommons@University of Nebraska - Lincoln. 


\section{Authors}

M.A. Schull, Y. Knyazikhin, L. Xu, A. Samanta, P.L. Carmona, L. Lepine, J.P. Jenkins, S. Ganguly, and R.B. Myneni 


\title{
Canopy spectral invariants, Part 2: Application to classification of forest types from hyperspectral data
}

\author{
M.A. Schull ${ }^{\text {a,* }}$, Y. Knyazikhin ${ }^{\text {a }}$, L. Xu ${ }^{\text {a }}$, A. Samanta ${ }^{a}$, P.L. Carmona ${ }^{\text {, }}$, L. Lepine ${ }^{\text {, }}$, J.P. Jenkins ${ }^{\text {, }}$, \\ S. Ganguly ${ }^{\mathrm{d}}$, R.B. Myneni ${ }^{\mathrm{a}}$ \\ a Department of Geography and Environment, Boston University, 675 Commonwealth Avenue, Boston, MA 02215, USA \\ ${ }^{\mathrm{b}}$ Departmento de Lenguajes y Sistemas Informáticos, Universitat Jaume I, Campus del Riu Sec, s/n, 12071 Castellón de la Plana, Spain \\ ${ }^{c}$ Complex System Research Center, University of New Hampshire, 8 College Road, Durham, NH 03824, USA \\ ${ }^{\mathrm{d}}$ Bay Area Environmental Research Institute, NASA Ames Research Center, Moffett Field, CA 94035, USA
}

\section{A R T I C L E I N F O}

Keywords:

Spectral invariants

Vegetation structure

Ecosystem

Scaling

Scattering albedo

Hyperspectral data

Radiative transfer

\begin{abstract}
A B S T R A C T
Many studies have been conducted to demonstrate the ability of hyperspectral data to discriminate plant dominant species. Most of them have employed the use of empirically based techniques, which are site specific, requires some initial training based on characteristics of known leaf and/or canopy spectra and therefore may not be extendable to operational use or adapted to changing or unknown land cover. In this paper we propose a physically based approach for separation of dominant forest type using hyperspectral data. The radiative transfer theory of canopy spectral invariants underlies the approach, which facilitates parameterization of the canopy reflectance in terms of the leaf spectral scattering and two spectrally invariant and structurally varying variables - recollision and directional escape probabilities. The methodology is based on the idea of retrieving spectrally invariant parameters from hyperspectral data first, and then relating their values to structural characteristics of three-dimensional canopy structure. Theoretical and empirical analyses of ground and airborne data acquired by Airborne Visible/Infrared Imaging Spectrometer (AVIRIS) over two sites in New England, USA, suggest that the canopy spectral invariants convey information about canopy structure at both the macro- and micro-scales. The total escape probability (one minus recollision probability) varies as a power function with the exponent related to the number of nested hierarchical levels present in the pixel. Its base is a geometrical mean of the local total escape probabilities and accounts for the cumulative effect of canopy structure over a wide range of scales. The ratio of the directional to the total escape probability becomes independent of the number of hierarchical levels and is a function of the canopy structure at the macro-scale such as tree spatial distribution, crown shape and size, within-crown foliage density and ground cover. These properties allow for the natural separation of dominant forest classes based on the location of points on the total escape probability vs the ratio $\log -\log$ plane.
\end{abstract}

(c) 2010 Elsevier Ltd. All rights reserved.
* Corresponding author. Tel.: +1 617353 8843; fax: +1 6173538846.
E-mail addresses: schull@bu.edu, bucricket@gmail.com (M.A. Schull).

\section{Introduction}

Vegetated land is a special type of surface where various physical, biogeochemical, physiological and meteorological processes and interactions between them 
determine the functioning of terrestrial ecosystems. Their distribution is largely controlled by climate and alternations of the ecosystem composition at local and landscape scales are ecological variables indicative of climate change $[1,2]$. Ecosystem changes in turn have the potential to influence regional climate via biophysical mechanisms $[3,4]$. Satellite remote sensing serves as the most effective means for mapping the current distribution of ecosystems globally, monitoring their status and improving our understanding of feedbacks among ecosystems, climate and disturbance. The scope of these activities is among the primary objectives of the Hyperspectral Infrared Imager (HyspIRI) mission [5] recommended for implementation by the US National Research Council [6].

Capabilities of hyperspectral data to detect ecosystem changes over a wide range of scales have been demonstrated in space- and airborne imaging spectrometer observations. The unique spectral signatures of plants have been used to discriminate and map dominant plant species and plant functional types [7-11]. It has been shown that hyperspectral data convey information about leaf physiological state [12], water content and evapotranspiration [13-15], vegetation chemical constituents such as nitrogen, lignin, and cellulose [13,16-19]. These results have employed the use of empirically based techniques, which are site specific, requires some initial training based on characteristics of known leaf and/or canopy spectra and therefore may not be extendable to operational use or adapted to changing or unknown land cover. Development of physically based approaches to interpret hyperspectral data is therefore required not only to take full advantage of the existing and proposed missions but also to advance our understanding of requirements for measurements of terrestrial ecosystem processes.

Spectral response of the vegetated surface to incident solar radiation results from interaction of photons with vegetation over wide range of scales. Challenges in developing physically based approaches to operationally interpret satellite data include an accurate quantification of the notion of scale and understanding of how variation in radiometric and structural properties of the vegetation at different scales impact the spectrum of radiation reflected by the vegetated surface [20-22]. The concept of canopy spectral invariants provides the required framework [26]. The approach expresses the observation that simple algebraic combinations of leaf and canopy spectra become wavelength independent and determine two spectrally invariant and structurally variant variables - the recollision and escape probabilities [21,23-26]. These variables specify an accurate relationship between the spectral response of a vegetation canopy to incident solar radiation at the leaf and the canopy scale [27]. They are sensitive to important structural features of the canopy such as tree geometry [28-30], stand age [31] and smallscale canopy structure [32-35]. The escape and recollision probabilities have the potential to separate forest types based on variability of canopy structure across multiple scales from leaves to canopies and stands. The objective of this paper is to demonstrate the feasibility of deriving distribution of dominant species from hyperspectral data using the concept of spectral invariants [26].
The paper is organized as follows. The concept of canopy spectral invariants and canopy spectral behavior at different scales are described in Sections 2, 3 and Appendix A. Method and data used to derive the spectral invariants and limitations of the proposed approach are discussed in Sections 4 and 5. The ability of the spectral invariants to discriminate dominant plant species is demonstrated in Section 6 and Appendix B. Finally, concluding remarks are given in Section 7.

\section{Theory}

The bidirectional reflectance factor (BRF) of a vegetated canopy bounded from below by a non-reflecting surface can be approximated as [22,25,26,30]

$B R F_{\lambda}=\frac{\omega_{\lambda}}{1-p \omega_{\lambda}} R\left(\Omega, \Omega_{0}\right)$

Here $R\left(\Omega, \Omega_{0}\right)=\rho(\Omega) i_{0}\left(\Omega_{0}\right)$ is an escape factor, $p$ and $\rho$ are the probabilities that a photon scattered from a phytoelement will interact within the canopy again (recollision probability, $p$ ), and escape the vegetation in a given direction $\Omega$ (escape probability, $\rho(\Omega)$ ) [25,26,32]. The integration of $\rho(\Omega)$ over all directions gives the portion, $1-p$, of canopy leaving photons, or the total escape probability. Further, $i_{0}\left(\Omega_{0}\right)$ is the probability of initial collisions, or canopy interceptance defined as the portion of incoming photons that collide with phytoelements for the first time. It does not depend on the wavelength and varies with the direction, $\Omega_{0}$, of the incident beam. The recollision and escape probabilities do not depend on the wavelength under certain conditions on leaf spectral transmittance and reflectance $[24,26]$. Finally, the probability of a scattering event is quantified by the wavelength-dependent scattering albedo $\omega_{\lambda}$.

Eq. (1) can be rearranged to a form, which we will use to retrieve the canopy spectral invariants $R\left(\Omega, \Omega_{0}\right)=\rho(\Omega) i_{0}\left(\Omega_{0}\right)$ and $p$ using hyperspectral reflectance data, namely

$\frac{B R F_{\lambda}}{\omega_{\lambda}}=p B R F_{\lambda}+R\left(\Omega, \Omega_{0}\right)$.

By plotting $B R F_{\lambda} / \omega_{\lambda}$, versus $B R F_{\lambda}$, a linear relationship is obtained, where the slope and intercept give the recollision probability, $p$, and the escape factor, $R[26,30]$. We will suppress the directional dependence in further notations.

Eq. (1) requires the use of a scattering albedo, $\omega_{\lambda}$, which depends on the scale, at which the quantity is defined. This is illustrated in Fig. 1. The vegetation canopy is idealized as a medium consisting of several hierarchical levels of structural organization. Each level is represented by objects distributed within a higher level. The object represents a clump of phytoelements (e.g., tree crown, shoot) or an individual element (e.g., leaf, needle). The scale is associated with the object size (e.g., crown scale, shoot scale, leaf or needle scale, etc.). The scattering albedo is the probability that a photon intercepted by an object will escape the object and therefore is a function of the object size, or scale. In Fig. 1 tree crowns distributed within a pixel ("level 0 ") constitute "level 1 " of canopy 


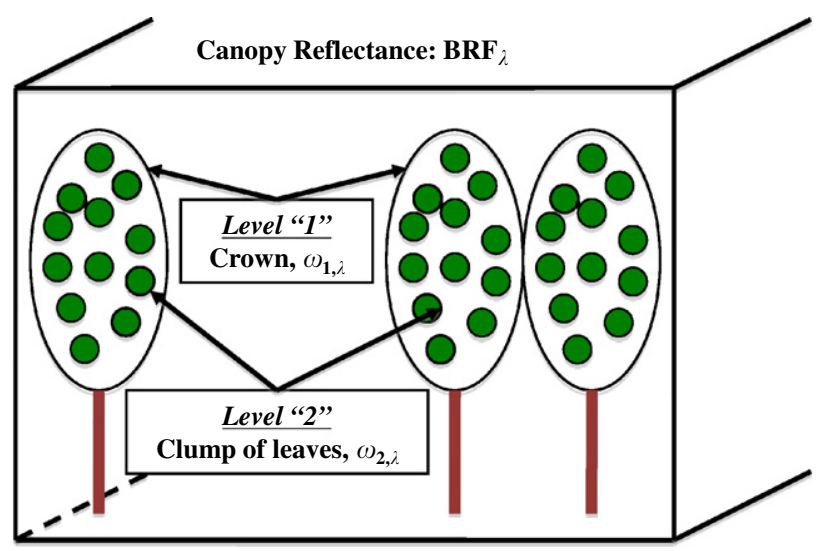

Fig. 1. Schematic of multi-level hierarchy of a forest. Shown are three nested levels: pixel (level 0), crown (level 1) and leaf clump (level 2) scales. Satellite-borne sensors measure the $B R F_{\lambda}$ of the pixel. Scattering properties of crowns and clumps are characterized by the scattering albedos $\omega_{1, \lambda}$ and $\omega_{2, \lambda}$, respectively.

structural organization. Each tree crown in turn consists of smaller objects (e.g., clumps of leaves) that form a second level of structural hierarchy, etc.

If the scattering albedo, $\omega_{1, \lambda}$, of a tree crown (object of level 1 ) is known (i.e., $\omega_{\lambda}$ in Eq. (1) represents $\omega_{1, \lambda}$ ), a line can be obtained using Eq. (2). The scattering albedo at the crown scale, $\omega_{1, \lambda}$, accounts for photon multiple interactions in the crown. The tree crown acts as a light trap: photons "travel" within it until being either absorbed or "find a way out." The latter can in turn either be trapped by another crown or escape the vegetation canopy through the space between crowns or within crown gaps of neighboring trees. The corresponding recollision and escape probabilities, $p_{1}$ and $\rho_{1}$, are the probabilities that a photon leaving the crown will recollide $\left(p_{1}\right)$ or escape the vegetation in a given direction $\left(\rho_{1}\right)$. They depend on properties of the canopy macro-scale structure such as tree spatial distribution, crown geometry and transparency; the latter depends on amount and distribution of phytoelements within crown. The escape factor $R_{1}$ is the directional escape probability $\rho_{1}$ multiplied by canopy interceptance $i_{0}$, thus $p$ and $R$ in Eq. (2) take values $p_{1}$ and $R_{1}$ at the crown scale.

In practice, the scattering albedo at crown scale however is not available. If we know the scattering albedo, $\omega_{2, \lambda}$, for a within crown clump (object of level 2 ), the crown scattering albedo can be expressed as [26,32]

$\omega_{1, \lambda}=\omega_{2, \lambda} \frac{1-p_{2,1}}{1-p_{2,1} \omega_{2, \lambda}}$.

Here $p_{2,1}$ is a local recollision probability, i.e., it refers to the clump scale (i.e. grouped branches, leaves, or needles) and quantifies the event that a photon scattered by a clump (object of level 2) will collide with another clump within the same crown (object of level 1). Substituting Eq. (3) into Eq. (1) we arrive at the same equation, however, with new values of the scattering albedo, escape factor and recollision probability given by $\omega_{2, \lambda}, R(2)=R_{1}\left(1-p_{2,1}\right)$, and $p(2)=p_{2,1}+$ $\left(1-p_{2,1}\right) p_{1}$, respectively. If the nesting procedure is repeated for $n, n>1$, hierarchical levels one arrives at

$B R F_{\lambda}=\frac{\omega_{n, \lambda}}{1-p(n) \omega_{n, \lambda}} R(n)$.

Here $\omega_{n, \lambda}$ is the scattering albedo of a "level $n$ " object and

$R(n)=\rho_{1} i_{0}\left(1-p_{2,1}\right)\left(1-p_{3,2}\right) \cdots\left(1-p_{n, n-1}\right)$,

$p(n)=1-\left(1-p_{1}\right)\left(1-p_{2,1}\right)\left(1-p_{3,2}\right) \cdots\left(1-p_{n, n-1}\right)$.

Eq. (4) links the spectral BRF of a pixel and spectral scattering of the "level $n$ " objects given by $\omega_{n, \lambda}$. The corresponding wavelength-independent recollision probability, $p(n)$, and escape factor, $R(n)$, are functions of the number of hierarchical levels and depend on the distribution of the "level $n$ " objects in the pixel. It follows from Eqs. (5) and (6) that recollision probability increases with the number of hierarchical levels (Eq. (6)), lowering the chance of an escape event (Eq. (5)). It should be emphasized that the recollision probability and escape factor depend on the scale at which scattering albedo is introduced.

Let $\kappa_{n-1}=\sqrt[n-1]{\left(1-p_{2,1}\right)\left(1-p_{3,2}\right) \cdots\left(1-p_{n, n-1}\right)}, n>1$, be the geometrical mean of local-only probabilities. Eqs. (5) and (6) can be expressed as power functions with the exponent related to the number of nested hierarchical levels present in the pixel,

$$
\begin{aligned}
& R(n)=R_{1} \kappa_{n-1}^{n-1}, n>1, R(1)=R_{1} \\
& 1-p(n)=\left(1-p_{1}\right) \kappa_{n-1}^{n-1}, n>1,1-p(1)=1-p_{1} .
\end{aligned}
$$

These equations have the following interpretation. Let the "level $n$ " object be a leaf. The factor $\kappa_{n-1}^{n-1}$ is the probability that a photon scattered by a leaf will pass through all $(n-1)$ levels and escape the "level 1" object (tree crown in Fig. 1). It will escape the vegetated layer in a given direction $\Omega$ through the gaps between crowns or within crown gaps of neighboring trees with the probability $\rho_{1} \kappa_{n-1}^{n-1}$. This gives a portion of leaves as seen from points outside the vegetated layer in the retro direction $-\Omega$. The integration of $\rho_{1} \kappa_{n-1}^{n-1}$ over all directions gives the total escape probability $(1-p(n))$ given by Eq. (8) which can be interpreted as a total amount of gaps as seen from every 
leaf in all directions. Their ratio $\rho_{1} \kappa_{n-1}^{n-1} /(1-p(n))$ therefore gives a relative portion of leaves seen from a given direction outside the vegetated layer. It follows from Eqs. (7)-(8) that the ratio becomes independent of the choice of the scattering albedo, is equal to $R_{1} /\left(1-p_{1}\right)$ and therefore is a function of the canopy structure at the coarsest scale such as tree spatial distribution, crown geometry and crown transparency. The latter depends on amount and distribution of phytoelements within the "level 1" object. In remote sensing applications this property gives us the flexibility in the selection of single scattering albedo needed to obtain the spectral invariants using Eq. (2). This will be discussed in the next section. Simulation of the "level 1" spectral invariants based on the stochastic radiative transfer equation is discussed in Appendix B.
One can see from the above relationships that it is more convenient to analyze variation in $|\ln (1-p(n))|$ and $|\ln R(n)|$ rather than $p(n)$ and $R(n)$ since the logarithm expresses the cumulative effect of various hierarchical levels of canopy organization via the summation of corresponding logarithms of the local total escape probabilities.

Eqs. (5)-(8) suggest an approach to extract information about canopy structure at both micro- and macro-scales. Indeed, $|\ln (1-p)|$ is proportional to the number of hierarchical levels in the canopy and accounts for the cumulative effect of canopy structure over a wide range of scales by accumulating the local probabilities. The recollision probability is a function of the scale at which the scattering albedo is defined. In contrast to the recollision probability, the ratio of the escape to the total escape

a

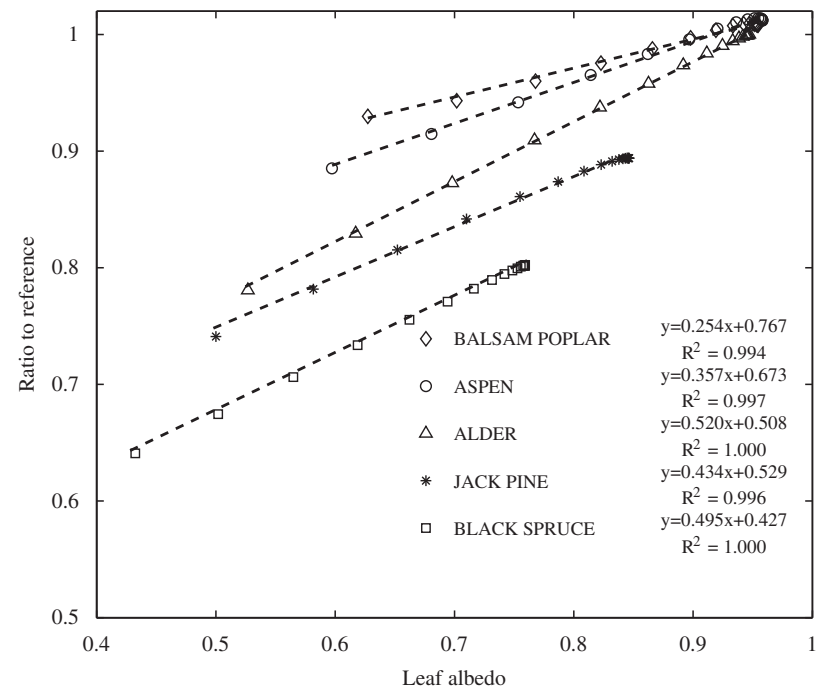

b

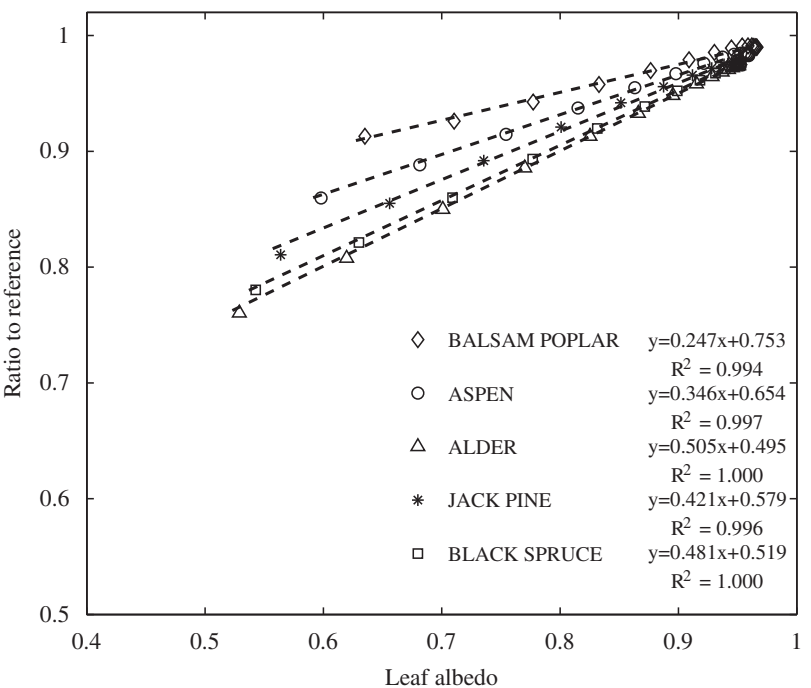

Fig. 2. (a) By plotting values of the ratio $W_{\lambda} / W_{\text {hazelnut, } \lambda}$ versus $W_{\lambda}$ for the spectral interval $[710 \mathrm{~nm}, 790 \mathrm{~nm}]$, a linear relationship is obtained. Here $W_{\text {hazelnut }, \lambda}$ is the mean measured albedo of hazelnut sample, and $W_{\lambda}$ represents measured spectra of aspen, alder, balsam poplar, black spruce, and jack pine samples. The slopes provide a measure of the difference between leaves/needles relative to the hazelnut leaf. (b) The measured spectra $W_{\lambda}$ should be normalized by the sample interceptance $i_{\mathrm{L}}$ to obtain albedo $\omega_{\lambda}=W_{\lambda} / i_{\mathrm{L}}$. The ratio $\omega_{\lambda} / \omega_{\mathrm{R}, \lambda}$ vs $\omega_{\lambda}$ is shown. 
probability does not depend on the choice of the scale and thus provides information about macro-scale features. The escape and recollision probabilities have the potential to separate forest types based on crown and stand geometry and the number of hierarchical levels within the landscape. This will be illustrated in Section 6 .

\section{Selection of the single scattering albedo}

In our approach, mean leaf (or needle) is taken as the finest scale. A question then arises as to how scattering properties at this scale can be specified. Lewis and Disney [35] found that Eq. (3) is applicable to the leaf and within leaf internal scattering, provided the concentration of absorbing constituents remains nearly constant across leaf samples. Their result suggests the existence of a reference leaf albedo $\omega_{\mathrm{R}, \lambda}$, i.e., an actual leaf albedo is related to the reference via Eq. (3) within spectral intervals where the impact of biochemical absorption on leaf/needle optical properties is minimized. This hypothesis, however, has not yet been proven. Therefore we analyzed measured leaf spectra available to us (Section 5.4) to see if their spectral variation follows Eq. (3). Fig. 2a shows relationships between the ratio $W_{\lambda} / W_{\text {hazelnut }, \lambda}$ versus $W_{\lambda}$ for the spectral interval between 710 and $790 \mathrm{~nm}$. Here $W_{\text {hazelnut, } \lambda}$ is the measured albedo of an average hazelnut leaf while $W_{\lambda}$ represents the remaining samples. One can see that the leaf albedo can be expressed via the hazelnut leaf spectrum, making it a candidate for the reference. However, the slope and intercept do not sum to unity as Eq. (3) predicts. This can be explained by measurement uncertainties: a portion of the photons reach the sensor without interacting with internal foliage constituents, e.g. due to gaps between needles positioned in an LI-1800-12 integrating sphere (Section 5.4). The measured spectra, therefore, should be normalized by the sample interceptance in order to obtain corresponding albedos $\omega_{\lambda}$ and $\omega_{\mathrm{R}, \lambda}$ (Fig. 2b). Our analyses suggest that the interceptance for jack pine and black spruce samples were 0.89 and 0.80 , and around 1 for broad leaves (see Appendix A). Note that interceptance values for needle samples agree with the accuracy of correction of measured spectra for gaps between needles, which ranges from $10 \%$ to $30 \%$ [36].

The BRF to albedo ratio versus BRF, relationships for dense patches of aspen and spruce shown in Fig. 3 illustrate that the hazelnut leaf albedo can be taken as the reference in this particular case. In the spectral interval between 710 and $790 \mathrm{~nm}$, leaf and needle spectral behavior is mainly dependent on the amount of dry matter and number of layers, i.e., the leaf and needle internal structure [37] and thus highly variable absorbing constituents do not have significant impact on the leaf albedo. In this spectral interval the structurally controlled BRF can be standardized to a single reference spectrum. The recollision probability (slope) becomes sensitive to both the number of canopy hierarchical levels and the structural difference between the known reference, $\omega_{\mathrm{R}, \lambda}$ and actual, $\omega_{\lambda}$, leaf or needle albedo. The latter is parameterized in terms of the slopes, $p_{n+1, n}$, shown in Fig. $2 \mathrm{~b}$ where $(n+1)$ stands for the within leaf level. For example the difference in the slopes of the Asp/Asp and Asp/Haz lines in Fig. 3 is due to the structural difference between the aspen and hazelnut leaves. Indeed, $\left|\ln \left(1-p_{\text {Asp } / \mathrm{Haz}}\right)\right|-\left|\ln \left(1-p_{\text {Asp } / \mathrm{Asp}}\right)\right|=\left|\ln \left(1-p_{n+1 . n}\right)\right|$ where $p_{n+1, n}=0.34$ (Fig. 2b). Thus $|\ln (1-p)|$ quantifies the cumulative effect of canopy structure over a wide range of scales, including leaf internal structure.

\section{Limitations of the method used}

The spectral invariant relationships are formulated for a vegetation canopy bounded from below by a nonreflecting surface. We used measured hyperspectral data

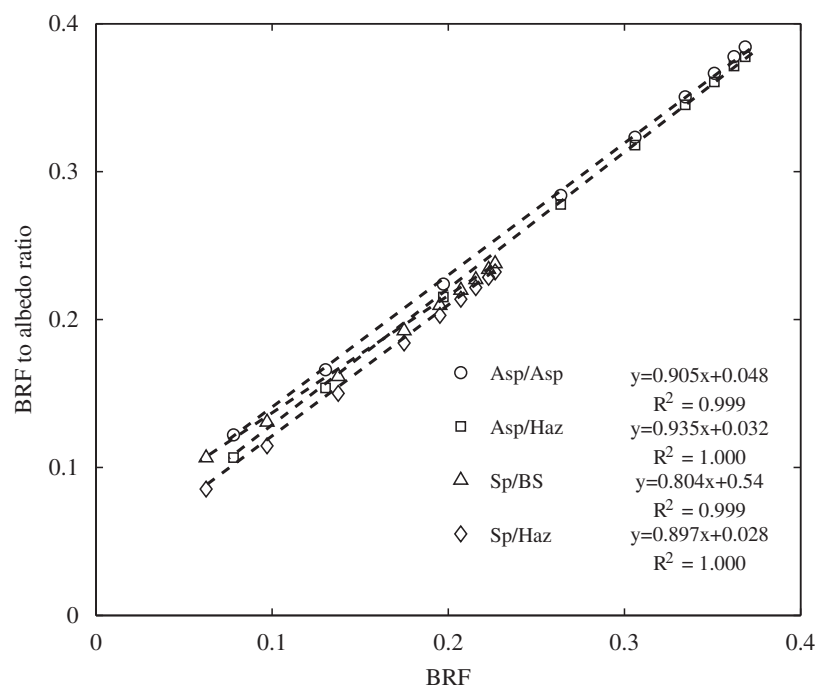

Fig. 3. $B R F_{\lambda} / \omega_{\lambda}$ versus $B R F_{\lambda}$, relationships for $90 \mathrm{~m}$ by $90 \mathrm{~m}$ dense patches of aspen and spruce at Bartlett forest using albedos of an average aspen (Asp/Asp), hazelnut (Asp/Haz and Sp/Haz) leaves and black spruce (Sp/BS) needle. AVIRIS reflectance in nadir viewing direction and albedos from the interval $[710 \mathrm{~nm}, 790 \mathrm{~nm}]$ were used. 


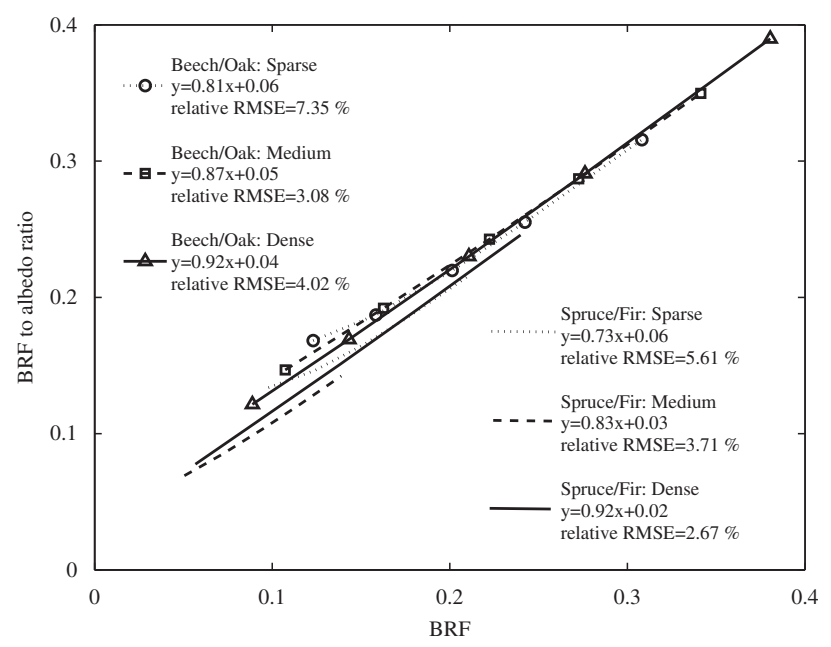

Fig. 4. Impact of background reflectance on the calculation of the spectral invariant parameters at the dominant broadleaf and the dominant needle leaf species at Bartlett Forest. NDVI for: sparse patches are 0.63 (beach/oak) and 0.65 (spruce/fir); medium patches are 0.88 (beech/oak) and 0.75 (spruce/fir); dense patches are 0.91 (beech/oak) and 0.93 (spruce/fir).

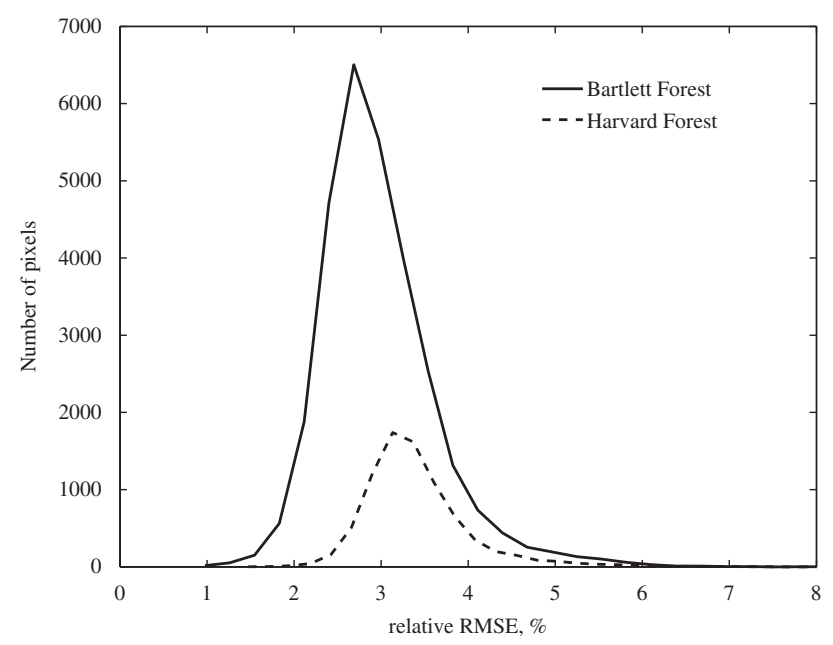

Fig. 5. Frequency of relative RMSE (\%) between measured and simulated BRF over Harvard and Bartlett Forests.

without removing canopy ground effects, which impact the values of the spectral invariants [25]. Therefore, we selected only pixels for which the impact of canopy background on the measured BRF is minimized. The selected pixels represent medium to dense forested stands, which were chosen based on values of the Normalized Difference Vegetation Index (NDVI). A pixel was attributed to medium to dense forest if the NDVI value was above 0.75 . As one can see from Fig. 4 linear relationships were achieved for medium to dense forests when applying Eq. (2). Fig. 5 shows the distribution of the Relative Root Mean Square Error (RRMSE) between measured BRF and BRF calculated with Eq. (1) over the study area. The RRMSE is defined as

$R R M S E^{2}=m^{-1} \sum_{\lambda=1}^{m}\left(\frac{\left(B R F_{\text {measured, } \lambda}-B R F_{\text {calculated }, \lambda}\right)}{B R F_{\text {measured }, \lambda}}\right)^{2}$.
RRMSE values for medium to dense patches do not exceed $4 \%$. Thus the recollision probability and escape factor are directly obtainable from the $B R F$ in this case. In general however the retrieval of the spectral invariants from spectral reflectance using Eq. (2) should follow after the removal of the background reflectance from the BRF of canopy-surface system.

The reflectance spectra were measured under ambient atmospheric conditions and then corrected for atmospheric effects (Section 5.2). We used wavelengths between 710 and $790 \mathrm{~nm}$. Under cloud-free conditions, the impact of the atmosphere on reflectance of a vegetated surface is minimal in this spectral interval $[25,30]$ and thus uncertainties due to the correction procedure are minimized. In addition both canopy reflectance and leaf albedo exhibit strong variation over this spectral range. Finally, variation in leaf albedo is 
mainly determined by leaf internal structure in this spectral interval [37]. This property allowed us to specify the reference leaf albedo for the study areas (Fig. 2).

\section{Data}

\subsection{Site description}

This research is focused on the New England sites of Harvard Forest in Massachusetts and Bartlett Experimental Forest in New Hampshire, USA. The Harvard Forest (latitude $42.54^{\circ} \mathrm{N}$, longitude $72.17^{\circ} \mathrm{W}$ ), a Long Term Ecological Research (LTER) site, is classified as a temperate deciduous forest with dominant species including red oak, red maple, black birch, white pine, and hemlock [WWW1]. The Bartlett Experimental Forest (latitude $44.06^{\circ} \mathrm{N}$, longitude $71.29^{\circ} \mathrm{W}$ ), a USDA Forest Service site, is mostly a broadleaf deciduous forest with areas of evergreen needleleaf in the upper elevations. There are areas of old-growth northern hardwoods with beech, yellow birch, sugar maple, and eastern hemlock being the dominant species. Even-aged stands of red maple, paper birch, and aspen occupy sites that were once cleared. Red spruce stands cover the highest slopes. The primary forest cover type is the sugar maple-beechyellow birch type. However, oak types are fairly common on southerly and westerly slopes [WWW2].

\subsection{AVIRIS data}

We used hyperspectral data from Jet Propulsion Laboratory's AVIRIS (Airborne Visible/Infrared Imaging Spectrometer) instrument flown on the ER-2 and the Twin Otter aircraft platforms [WWW3]. The ER-2 aircraft was flown over Bartlett Forest at approximately $20 \mathrm{~km}$ above sea level on August 24, 2003 (SZA of $37.63^{\circ}$ ), resulting in a pixel size of about $15.7 \mathrm{~m}$ and a $11 \mathrm{~km}$ wide swath. In addition, the Twin Otter aircraft was flown over Harvard Forest at $4.3 \mathrm{~km}$ above ground level on September 6, 2002 (SZA of $37.54^{\circ}$ ), allowing for $3.3 \mathrm{~m}$ spatial resolution and a $3 \mathrm{~km}$ swath width. AVIRIS is a "whisk broom" scanner that captures upwelling spectral radiance in 224 contiguous spectral bands at wavelengths from 400 to $2500 \mathrm{~nm}$ with a $10 \mathrm{~nm}$ nominal bandwidth $[38,39]$.

The AVIRIS data was atmospherically corrected using the Fast Line-of-sight Atmospheric Analysis of Spectral Hypercubes (FLAASH) module in ENVI [39]. The atmospherically corrected data was then re-sampled to $30 \mathrm{~m}$ spatial resolution using the nearest neighbors approach. The spectral range of FLAASH is $400-2500 \mathrm{~nm}$, however, the data were subset to $400-1000 \mathrm{~nm}$ range to eliminate any noisy wavelengths and to match the spectral range of the available leaf spectra described in Section 5.4. The AVIRIS sensor is comprised of 4 sensors, 2 of which overlap at approximately $655 \mathrm{~nm}$. To eliminate redundancy in the data set we simply removed duplicate bands, 655.09, 664.79 and $675.78 \mathrm{~nm}$.

\subsection{Species maps}

The New Hampshire land cover data set, derived using $30 \mathrm{~m}$ resolution Landsat 5 and 7 TM scenes, is used for our
Table 1

Bartlett Forest dominant species distribution for a $30 \mathrm{~m}$ spatial resolution from an area of $5.5 \mathrm{~km} \times 4.75 \mathrm{~km}$. Total number of pixels for the classified species is 27274 .

\begin{tabular}{lll}
\hline Species & Number of pixels & Percent of total \\
\hline Beech/oak & 5917 & 21.69 \\
Paper birch/aspen & 3915 & 14.35 \\
Other hardwoods & 6803 & 24.94 \\
Spruce/fir & 2793 & 10.24 \\
Hemlock & 1551 & 5.69 \\
Red/white pine & 627 & 2.29 \\
Mixed forest & 5668 & 20.78 \\
\hline
\end{tabular}

Table 2

Harvard Forest dominant species distribution for a $30 \mathrm{~m}$ spatial resolution from an area of $3 \mathrm{~km} \times 3 \mathrm{~km}$. Total number of pixels for the classified species is 3403 .

\begin{tabular}{lcc}
\hline Species & Number of pixels & Percent of total \\
\hline Red oak & 1170 & 34.37 \\
Red maple & 805 & 23.65 \\
White pine & 539 & 15.83 \\
Hemlock & 563 & 16.54 \\
Red pine & 326 & 9.58 \\
\hline
\end{tabular}

analysis at Bartlett Forest [WWW4]. The 23-class land cover map emphasizes agriculture and forest classes, however in our study area we use only the dominant forest classes (see Table 1). An accuracy assessment was generated using 975 sites as a sample size. An error matrix showed an overall accuracy of $82.2 \%$, however, an additional fuzzy accuracy assessment was conducted [40] which yielded $92.0 \%$ accuracy. The classification was spatially subset to match the study area and was then geo-referenced to the AVIRIS data set for Bartlett Forest.

The species distribution map at Harvard Forest was derived from the LTER's Harvard Forest Properties GIS dataset $[41,42]$. Plot level data were collected in situ from 1986 to 1993 where upon data was used to digitize polygons of tree stand for 40 species. We use the dominant forest types for the data available (see Table 2). The digitized dataset was then rasterized and re-sampled to a spatial resolution of $30 \mathrm{~m}$. The resultant image was then geo-referenced to match the AVIRIS data set for Harvard Forest.

\subsection{Leaf spectra}

Leaf spectra were taken during the Boreal Ecosystem Atmosphere Study (BOREAS) Campaign [WWW5] from May to September of 1994. Measurements of leaf spectra were made using the LICOR LI-1800-12 integrating sphere in combination with the Spectron Engineering SE590 spectro-radiometer [43]. The sensor collects hemispherical leaf spectral reflectance and transmittance at a spectral resolution of $5 \mathrm{~nm}$ over a range $400-1000 \mathrm{~nm}$. We matched the spectral resolution of the BOREAS leaf albedo dataset of $5 \mathrm{~nm}$ to AVIRIS by taking the mean of the bands that fall within the lower and upper edges of 
Table 3

BOREAS campaign leaf albedo collection.

\begin{tabular}{llll}
\hline Species & Site location & Dates (1994) & Canopy location (sample size) \\
\hline Aspen & SSA-9OA SSA-9YA & $05 / 29,06 / 04,06 / 05,06 / 13,07 / 29,09 / 04,09 / 07$ & Top (81), middle $(80)$ bottom (47) \\
Alder & SSA-9YA & $07 / 29$ & Under $(9)$ \\
Hazelnut & SSA-9YA & $07 / 29$ & Under $(12)$ \\
Balsam poplar & SSA-9YA & $07 / 29$ & Under $(12)$ \\
Black spruce & SSA-OBS & $07 / 31,08 / 03,09 / 05,09 / 08$ & Top $(135)$, bottom $(183)$ \\
Jack pine & SSA-YJP & $05 / 29,06 / 11,07 / 23,07 / 26,09 / 12,09 / 15$ & Top $(210)$, bottom $(244)$ \\
\hline
\end{tabular}

the AVIRIS bandwidths. Measurement procedures followed the methods described in Daughtry et al. [44], where needle leaf measurements were taken using a modified technique to take into account the gaps between needles. The error associated with the measurements ranged from $10 \%$ to $30 \%$, with most of the error resulting from the gap analysis of the needles [36]. We account for the error associated with gaps by applying a correction based on a correction factor (see Appendix A).

The samples of leaves and needles were taken at different times and from different locations in the canopy as well as at different site locations (see Table 3). We used the mean value of adaxial and abaxial leaf albedo over all available samples of green leaf spectrum. Different gap analysis techniques were used before and after April of 1994, therefore to retain consistency we used only measurements taken after April of 1994.

\section{Results and discussions}

Fig. 6 illustrates the separation of forest classes in the spectral invariant space for Bartlett and Harvard forests for nadir viewing direction. The vertical axis, $|\ln (1-p)|$, is related to the number of hierarchical levels within the pixel, while the ratio of the escape factor $R$ to the total escape probability, $1-p$, (horizontal axis) is independent of the number of levels and varies with tree spatial distribution, crown geometry and transparency (Section 2). Recall that we account for the within leaf/needle level parameterized in terms of the hazelnut leaf (Section 3 and Fig. 2b). This level is designated as $n+1$. The location of a point in this space, therefore, depends on properties of the canopy structure at both micro- (vertical axis) and macro(horizontal axis) scales.

Note that both the vertical, $y=\left|\ln \left(1-p_{1}\right)\right|+n\left|\ln \kappa_{n}\right|$, and horizontal, $x=-\left|\ln \left(1-p_{1}\right)\right|+\left|\ln \left(R_{1}\right)\right|$, coordinates of the point include the term $\left|\ln \left(1-p_{1}\right)\right|$. Its location can be obtained by shifting a point on the $-1: 1$ line by $\left|\ln \left(R_{1}\right)\right|$ along the horizontal axis, and by $n\left|\ln \kappa_{n}\right|$ along the vertical axis. This simple property explains the tendency for points to follow a $y=-x+b$ line. A deviation from this line is due to variation in $R_{1}$ and $\kappa_{n}^{n}$. Therefore we will start our interpretation by tracking the points from the $-1: 1$ line to its actual position.

A value of $\left|\ln \left(1-p_{1}\right)\right|$ determines the location of a point on the $-1: 1$ line. The "level 1 " recollision probability, $p_{1}$, of "a crown leaving photon recollision" mainly depends on the tree spatial distribution, crown geometry and crown transparency. In our example, the selected pixels represent medium to dense forests (Section 4). In the case of broad leaf forest, the crowns are generally ellipsoidal to spherical in shape and form a fairly smooth surface, enhancing the chance of a between crown recollision event. This effect is illustrated in Fig. 7 which shows simulated "level 1 " recollision probability $p_{1}$ as a function of the aspect ratio (crown height to crown diameter) for ellipsoidal and conical shaped tree crowns, different values of ground cover and a fixed value of the canopy leaf area index (one sided leaf area per unit ground area).

Needle leaf crowns are ellipsoidal to conical in shape with generally a higher value of aspect ratio. In needle leaf forests the upper canopy exhibits a higher heterogeneity due to the fact that conical crowns form a 3D surface even when the ground cover is high. This increases the probability for photons to escape the vegetation through the crown lateral surface (Fig. 7), lowering the location of the needle leaf pixels on the $-1: 1$ line. In the mixed forest the coexisting broad leaf species (hardwoods) fill in the gaps, smoothing the resulting top of canopy topology. As a result, the mixed forest class occupies a space between broadleaf and needle leaf forests. This feature is evident at Bartlett forest as seen in Fig. 6b.

The horizontal shift is determined by the "level 1"escape factor, $R_{1}\left(\Omega, \Omega_{0}\right)=\rho_{1}(\Omega) i_{0}\left(\Omega_{0}\right)$, that "a photon exiting the crown will escape the vegetation in a given direction, $\Omega$." The escape probability, $\rho_{1}(\Omega)$, is related to number of leaves as seen from above the canopy in the retro direction (Section 2). The total "level 1" escape probability, $\left(1-p_{1}\right)$, can be interpreted as a total amount of gaps as seen from every leaf/needle in all directions. The ratio, $\rho_{1}(\Omega) /\left(1-p_{1}\right)$, therefore gives a relative portion of leaves seen from a given direction. In our example, clumps (groups of branches and leaves) in broadleaf forest are relatively large and sparse. This feature increases the chance for scattered photons to escape the crown. However the high density of the forest enhances the chance of between crown recollision. Photons are more likely to escape the broadleaf forest through the upper part of the crown, resulting in a relatively high value of $\rho_{1}(\Omega) /\left(1-p_{1}\right)$ in upper directions (Fig. 8). In the needle leaf forest, clumps (shoots) are dense and small in size compared to broad leafs. This significantly reduces number, $\rho_{1}(\Omega)$, of scattering centers (needles) seen from the above canopy in a given direction. A higher probability, $\left(1-p_{1}\right)$, of a crown leaving photon to escape the vegetation canopy (Fig. 7) lowers the ratio $\rho_{1}(\Omega) /$ $\left(1-p_{1}\right)$ (Fig. 8). In our example the ratio $\rho_{1}(\Omega) /\left(1-p_{1}\right)$ 


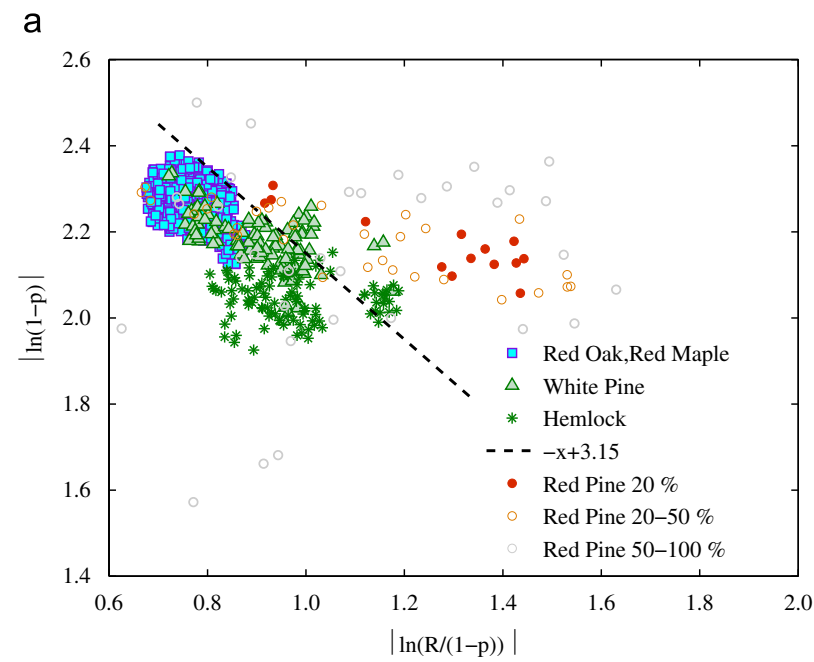

b

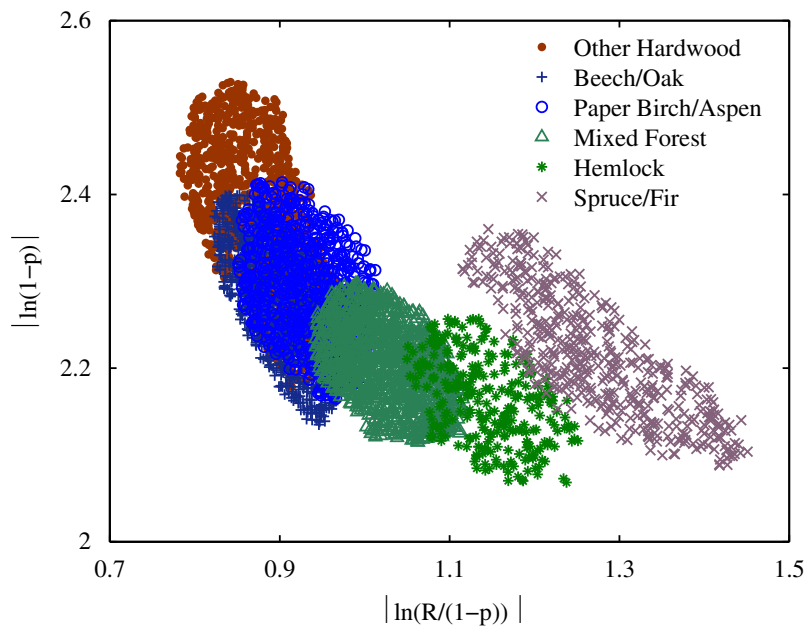

Fig. 6. Spectral invariant space for Harvard Forest (Panel a) and Bartlett Forest (Panel b) for nadir viewing direction. The vertical axis, $|\ln (1-p)|$, is related to the number, $n$, of hierarchical levels within the pixel (e.g., the clumping of needles into shoots, shoots and leaves into crowns, etc.), while the ratio of the escape factor $R$ to the total escape probability, $1-p$, (horizontal axis) is independent of $n$ and varies with tree spatial distribution, crown geometry and within crown foliage distribution and density. The location of the points in this space depend on properties of the canopy structure at both micro(vertical axis) and macro-(horizontal axis) scales. The points shown here represent the top 20 percent densest location for a density plot. Additionally Harvard Forest is shown here for fixed LAI $=4.5$ ( $S T D=0.27$ ). Dashed line shows the $-1: 1$ line shifted by 3.15 along the horizontal axis. Note that Red Pine is shown here for the densest $20 \%$ (as in a density plot) in red filled circles, $20-50 \%$ densest in orange circles and the remaining in grey circles (For interpretation of the references to color in this figure legend, the reader is referred to the web version of this article.)

tends to take on smaller values for needle leafs (Fig. 6). The ground cover also impacts the ratio as a decrease in the ground cover diminishes the relative number of scattering centers (leaves or needles) seen from a particular direction. In our example a lower ground cover explains the Red Pine's location in the spectral invariant space (Fig. 6a).

It should be noted that the horizontal shift depends on the initial collision $i_{0}$. Rautiainen et al. [33] found that the relationship of effective LAI (obtained by inversion LAI2000 data using the Beer-Lambert law) and diffuse non-interceptance, $\left(1-i_{0}\right)$, is near universal (in boreal forest), i.e., it does not depend on stand age, tree species or growth conditions. This finding suggests that at a given effective LAI the contribution of the term $\left|\ln i_{0}\right|$ has minimal impact on the relative locations of the points in the spectral invariant space. The distribution of points for the Harvard Forest where $\mathrm{LAI}$ is fixed $(\mathrm{LAI}=4.5, \mathrm{STD}=0.27)$ shown in Fig. 6a does not reject this hypothesis.

Finally, the vertical shift is determined by $n\left|\ln \kappa_{n}\right|$ and depends on the number of hierarchical levels as well as the geometrical mean, $\kappa_{n}$, of the local total escape probabilities (Section 2). Broad leafs may exhibit higher number, $n$, of nested clumps due to their branch structure. Clumps (groups of leaves on a branch) are relatively large and sparse, resulting in low values of the local recollision probabilities. The former enhances the contribution of the small-scale structure variability while the latter suppresses it. Unfortunately we have no data on crown structure or models to either support or reject this 


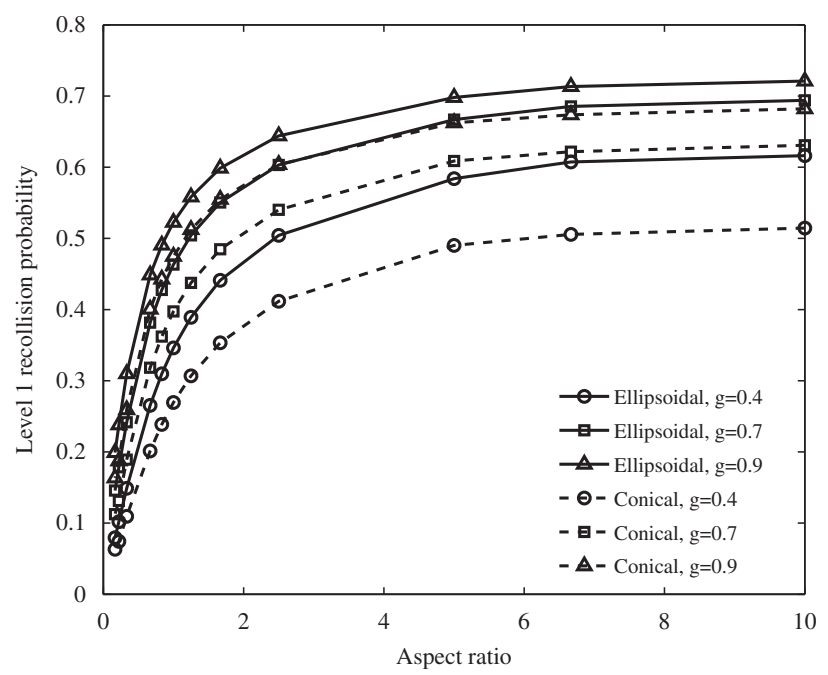

Fig. 7. Probability that a crown leaving photon "will recollide" as a function of the aspect ratio (crown height to crown diameter) for different values of the ground cover $g$. Poisson germ-grain models of a forest consisting of identical conical and ellipsoidal shaped trees are used to simulate canopy structure. Canopy LAI is fixed and set to 4.5. See Appendix B for details.

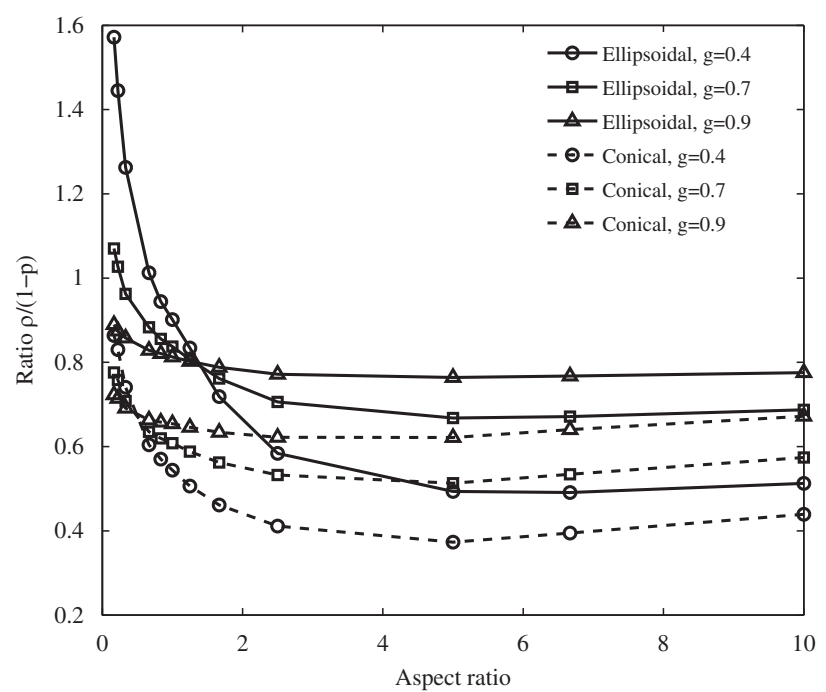

Fig. 8. Simulated ratio $\rho /(1-p)$ as a function of the aspect ratio for different values of the ground cover $g$. Canopy LAI is fixed and set to 4.5. Details are given in Appendix B.

hypothesis at this point. Further research is required to validate or reject the hypothetical explanation of the vertical shift in this case.

In needle leaf forests, differences in shoot structure may result in a detectable vertical shift. In our examples (Fig. 6), the Hemlock class tends to occupy a lower location in the spectral invariant space compared to the spruce/fir/pine classes. A hemlock shoot is flat and its local recollision probability, $p_{n, n-1}$, is close to zero. The spruce/fir/pine shoot exhibits a dense packing of needle area in the shoot. Its spherically averaged shoot silhouette to total area ratio ( $\overline{\text { STAR }}$ ) parameter [45] can be as low as 0.1 [46,47], giving a high value of the local (shoot) recollision probability, $p_{n, n-1}=1-4 \overline{\mathrm{STAR}}=0.53$ [48]. At the same $R /(1-p)$, therefore, the Hemlock class occupies a lower position relative to its Spruce/Fir/Pine counterpart due to differences in the shoot structure.

It should be noted that the leaf internal structure also contributes to the vertical shift. Its amplitude is determined by the difference, $p_{n+1, n}$, between the reference and actual leaf albedo (Fig. 2b) and is given by $\left|\ln \left(1-p_{n+1, n}\right)\right|$ (Section 3). In this particular example, the needle albedos almost equally depart from the reference (Fig. 2b), suggesting that the vertical shift is determined by the shoot structure. In the case of broadleaf class however the difference exhibits a higher variation (Fig. 2b), making the analysis difficult. Moreover the reference leaf albedo used in our study is based on the leaf albedos collected during the BOREAS field campaign (Section 5.4) and therefore may not represent all leaves. The reference 
albedo is still an open question and further research needs to be conducted to fully explain and find a reference leaf albedo in order to provide the unambiguous interpretation of the distribution of points in the spectral invariant space.

To summarize, the distribution of points in the spectral invariant space depends on properties of the canopy structure at both macro- and micro-scales. Stand geometry such as crown shape and volume, ground cover and within-crown density controls the distribution of points along the $-1: 1$ line. Crown internal structure such as the sizes and densities of clumps are responsible for the deviation of points from the line in the horizontal direction. Finally, the number of hierarchical levels and the complexity of each level determine variation of points along the vertical axis.

\section{Conclusions}

The theoretical and empirical analyses suggest that the recollision and directional escape probabilities convey information about canopy structure at both the macroand micro-scales. The total escape probability (one minus recollision probability) is a power function. Its exponent is related to the number of nested hierarchical levels within the pixel (e.g., crown hierarchical branch structure, clumping of needles into shoots, shoots and leaves into crown, etc.). The base is a geometrical mean of the local total escape probabilities. The local recollision probability refers to a particular clump (e.g., crown, or shoot) and quantifies the event that a photon scattered within the clump (e.g., within crown, or within shoot) will interact within the same clump again (e.g., within the same crown, or within the same shoot). The recollision probability accounts for the cumulative effect of canopy structure over a wide range of scales by accumulating the local probabilities. The ratio of the directional to the total escape probability however becomes independent of the number of nesting hierarchical levels and is a function of the canopy structure at the macro-scale such as tree spatial distribution, crown shape and size, within-crown foliage density, and ground cover. These properties allow for the natural separation of dominant forest classes based on the location of points on the total escape probability vs the ratio log-log plane.

The theory of canopy spectral invariants specify a very accurate and physically justified relationship between the spectral response of a vegetation canopy to incident solar radiation at leaf to canopy scales and thus provides a strong physical basis for interpretation of hyperspectral data. The theory requires the use of the leaf albedo spectrum to specify the spectral invariants, however, this information is not available in the interpretation of satellite data. By analyzing data on leaf optical properties collected during the BOREAS campaign we have found that the mean measured spectra of a green leaf and a needle in the interval between about $710 \mathrm{~nm}$ and about $790 \mathrm{~nm}$ can be expressed via the mean spectrum of a hazelnut leaf. This finding suggests the existence of a reference leaf albedo, i.e., a given leaf albedo can be transformed from the reference using spectral invariant relationships. We have shown that the use of the reference leaf albedo in place of the actual leaf albedo does not violate the spectral invariant relationships and thus can be exploited to derive the recollision and escape probabilities. This property allows for the expression of variations in spectral invariants relative to one fixed and known albedo. It has been shown that if the reference leaf albedo does exist, the ratio of the directional escape factor to the total escape probability becomes independent of the choice of the single scattering albedo.

The presence of the reference leaf albedo appears to exist however it has not yet been proven. The search for possible models for the reference leaf albedo and understanding the physical reasons for this phenomena are essential to the development of physically based algorithms for interpretation of hyperspectral data since it allows for the unambiguous separation of the structural and radiometric components of the measured spectra.

\section{Acknowledgements}

This research was funded by the Jet Propulsion Laboratory, California Institute of Technology under MISR contract 1259071 , by the National Aeronautics and Space Administration (NASA) under Grants NNX08AE81G, NNX09AI30G, NNX08AL55G, NNX08AE89A, and by NASA Headquarters under the NASA Earth and Space Science Fellowship Program under Grant NNX07AO41H. P. Latorre Carmona received partial support through Spanish Ministry of Science and Innovation under Grant AYA200805965-C04-04/ESP.

\section{Appendix A. Correction of measured needle spectra for gaps}

The leaf reflection $(R)$ measured by the LI-1800 integrating sphere comes from interactions with the leaf surface $\left(\omega_{\infty}\right)$ and with internal leaf biochemical constituents $\left(R_{\mathrm{L}}\right)$. The quantity $\omega_{\infty}$ varies with leaf refractive index and is on the order of $10^{-2}$ [35]. On the assumption that the leaf surface does not absorb radiation, the leaf reflection is then obtained as

$R=\omega_{\infty}+\left(1-\omega_{\infty}\right) R_{\mathrm{L}}$

The measured leaf transmission $(T)$ accounts for photons that reach the sensor without interacting with leaf/needle surface $\left(t_{0}\right)$ and photons that have undergone interaction with internal leaf constituencies $\left(T_{\mathrm{L}}\right)$, i.e.,

$T=\left(1-\omega_{\infty}\right) t_{0}+\left(1-\omega_{\infty}\right) T_{\mathrm{L}}$.

Let $\omega=\left(T_{\mathrm{L}}+R_{\mathrm{L}}\right) /\left(1-t_{0}\right)$ be the transformed leaf albedo, which is the probability of being scattered from the leaf given that photon interacts with internal leaf constituents [35]. This quantity follows spectral invariant relationship [35]. The measured leaf spectra $(W)$ is related to the leaf albedo $(\omega)$ as $W=T+R=\left(1-i_{\mathrm{L}}\right)+\omega i_{\mathrm{L}}$ where $i_{\mathrm{L}}=\left(1-t_{0}\right)$ $\left(1-\omega_{\infty}\right)$. For $\omega \gg 1-i_{\mathrm{L}}$

$W=\omega\left[\frac{1-i_{\mathrm{L}}}{\omega}+i_{\mathrm{L}}\right] \approx \omega i_{\mathrm{L}}$. 
Thus one needs to specify the correction factor $\left(i_{\mathrm{L}}\right)$ in order to convert the measured albedo to its true value.

Since the measurements of needles include gaps the leaf interceptance, $\left(1-t_{0}\right)$, can be lower than 1 . This error leads to more transmittance, which allows for sum of the slope and intercept, as seen in Fig. 2a, to be not equal to unity. Let $\omega_{\mathrm{R}}$ and $i_{\mathrm{R}}$ denote the reference leaf albedo and corresponding value of the leaf interceptance, respectively. In our case the reference is given by the measured albedo ( $\left.W_{\text {hazelnut }}\right)$ of an average hazelnut leaf. By plotting values of the measured ratio $W / W_{\text {hazelnut }}$ versus $W$, a linear relationship is obtained (Fig. 2a). Let $k$ and $b$ be its slope and intercept. Substitution of (A3) and $W_{\text {hazelnut }}=\omega_{\mathrm{R}} i_{\mathrm{R}}$ into the linear relationship yields $\omega / \omega_{\mathrm{R}}=k i_{\mathrm{R}} \omega+\left(i_{\mathrm{R}} / i_{\mathrm{L}}\right) b$. Since the leaf albedos follow the spectral invariant relationship with a slope and intercept that sum to unity, $p=k i_{\mathrm{R}}$, and $1-p=\left(i_{\mathrm{R}} / i_{\mathrm{L}}\right) b$. Solving these equations for $i_{\mathrm{L}}$ gives

$i_{\mathrm{L}}=\frac{i_{\mathrm{R}} b}{1-k i_{\mathrm{R}}}$.

We set the correction factor $i_{\mathrm{R}}$ for the reference albedo to 0.97 to get values of the remaining factors as close to

\section{Table A1}

Slope $(k)$ and intercept $(b)$ of the linear relationship $(y=k x+b)$ between the measured ratio $\left(y=W / W_{\text {hazelnut }}\right)$ and measured albedo $(x=W)$, their sum $(k+b)$, the level $n+1$ local recollision probability $(p)$ and correction factor $\left(i_{\mathrm{L}}\right)$ assuming $i_{\mathrm{R}}=0.97$.

\begin{tabular}{llllll}
\hline Parameter & Aspen & Alder & $\begin{array}{l}\text { Balsam } \\
\text { poplar }\end{array}$ & $\begin{array}{l}\text { Black } \\
\text { spruce }\end{array}$ & $\begin{array}{l}\text { Jack } \\
\text { pine }\end{array}$ \\
\hline Slope, $k$ & 0.36 & 0.52 & 0.25 & 0.49 & 0.43 \\
Intercept, $b$ & 0.67 & 0.51 & 0.77 & 0.43 & 0.53 \\
$k+b$ & 1.03 & 1.03 & 1.02 & 0.92 & 0.96 \\
$p=i_{\mathrm{R}} k$ & 0.35 & 0.51 & 0.25 & 0.48 & 0.42 \\
$i_{\mathrm{L}}=i_{\mathrm{R}} b /$ & 0.9989 & 0.9957 & 0.9882 & 0.7965 & 0.8863 \\
$\quad\left(1-i_{\mathrm{R}} k\right)$ & & & & & \\
\hline
\end{tabular}

unity as possible. Table A1 summarizes values of the slope $(k)$, intercept $(b)$, level $(n+1)$ local recollision probability and the correction factor for aspen, alder, balsam poplar leaves, black spruce and jack pine needles.

\section{Appendix B. Simulation of the level 1 recollision and escape probabilities}

A Poisson germ-grain model of a forest consisting of identical trees is used to simulate canopy structure in a pixel of area $S[49,50]$. Tree crowns in the pixel are represented by a vertical solid, i.e., a volume obtained by rotating a curve about the vertical axis. Their centers are scattered on $S$ according to a stationary Poisson point process of intensity $d$ (in stem per unit area). Nondimensional leaves are assumed to be uniformly distributed and spatially uncorrelated within tree crowns. The amount of leaf area in the tree crown is parameterized in terms of the leaf area volume density $d_{\mathrm{L}}\left(\right.$ in $\mathrm{m}^{2} / \mathrm{m}^{3}$ ). Uniform and bi-Lambertian models are assumed for the leaf normal distribution and the leaf scattering phase function, respectively [51,21]. Leaf hemispherical reflectance and transmittance are assumed to have the same value. This model has two hierarchical levels $(n=2)$.

The stochastic radiative transfer equation is used to obtain vertical profiles of a horizontally averaged 3D radiation field and its second moment [52-54,50]. The latter is the mean intensity of radiation incident on the leaf surface at depth $z$. A detailed description of the stochastic radiative transfer equation used in our simulations can be found in [50].

Under the above assumption the fraction, $a(z)$, covered by tree crowns at depth $z$ (dimensionless) is given by $[49,50]$

$a(z)=1-\exp \left\{-d \pi r^{2}(z)\right\}$,

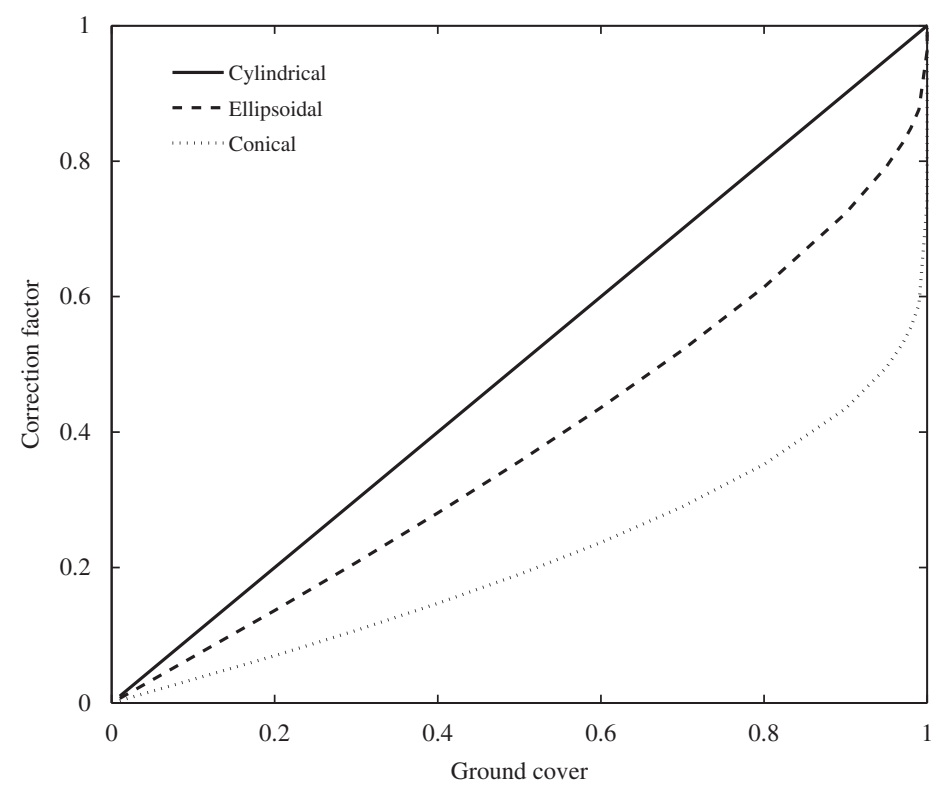

Fig. B1. Correction factor $\Phi(g)$ as a function of the ground cover for spherical, conical and cylindrical in shape trees. 
where $r(z)$ is the radius of the horizontal cross section of the vertical solid at depth $z$. The fraction is an important variable characterizing the roughness of the upper canopy surface formed by the tree crowns: the lower its value at $z$, the more between crown gaps at this depth. Let $R=\max _{z} r(z)$. The canopy ground cover, $g$, takes the following form:

$g=a(R)=1-\exp \left\{-d \pi R^{2}\right\}$.

Solving Eq. (B2) for $d \pi$ and substituting the solution into Eq. (B1) yields

$a(z)=1-(1-g)^{\rho(z)}$,

where $\rho(z)=r^{2}(z) / R^{2}$. Thus the fraction $a(z)$ is parameterized in terms of the ground cover $g$ and vertical shape $\rho(z)$ of the tree crown. We use the aspect ratio, $A$ (crown height to crown diameter), to parameterize crown horizontal dimension, i.e., $2 R=H / A$.

The canopy LAI is given by

$L A I=d_{L} \int_{0}^{H} a(z) d z=d_{L} H \int_{0}^{1}\left[1-(1-g)^{\rho(\xi H)}\right] d \xi=L_{0} \Phi(g)$.

Here $L_{0}=d_{\mathrm{L}} H$ (dimensionless) is the optical height of the tree crown and $\Phi(g)$ represents the integral term in Eq. (B4). Fig. B1 shows the factor $\Phi(g)$ for cylindrical $(\rho(\xi H)=1)$, conical $\left(\rho(\xi H)=\xi^{2}\right)$ and ellipsoidal $(\rho(\xi H)=$ $4 \xi(1-\xi)))$ shaped crowns.

Under the above assumptions on the stochastic model of canopy structure the corresponding solution of the stochastic radiative transfer equation depends on the crown optical height, $L_{0}$, vertical shape $\rho(z)$ of the tree crown, the aspect ratio $A$ and ground cover $g$. Since these structural parameters are expressed relative to the crown height $H$, the latter can be set to 1 .

In Harvard Forest, measured LAI values of selected pixels vary between 4 and 5 . Mean LAI and standard deviation are 4.5 and 0.27 , respectively. In our calculations, canopy LAI and crown height, $H$, are fixed and set to 4.5 and 1 (in relative units), respectively. The optical crown height $L_{0}$ varies with ground cover as $L_{0}=4.5 / \Phi(g)$. It means that an increase in ground cover is accompanied by a decrease in the within crown foliage density. Note that crown volume, $V$, is inversely proportional to the second power of the aspect ratio, i.e., $V=\pi k H^{3} / A^{2}$ where $k$ takes on the value $1 / 6$ for ellipsoidal and $1 / 12$ for conical in shape crowns. Since the crown height is fixed in our calculations, variation in the aspect ratio means variation in the crown volume. At a given ground cover, variation in volume does not involve changes in the within crown foliage density.

The recollision probability varies with the number of successive interactions. It converges to the maximum eigenvalue of the radiative transfer equation very fast [25]. Here we present the eigenvalue as a function of the aspect ratio for different values of the ground cover using the approach described in [25]. The calculations were organized as follows. First, we calculate eigenvalues for a single tree (Fig. B2). This is the local recollision probability $p_{2,1}$ (Section 2). Second, we calculate eigenvalues of the radiative transfer equation for forests consisting of identical trees that correspond to $p_{2}$ (Fig. B3). The level 1 local recollision probability $p_{1}$ shown in Fig. 7 was estimated using equation $p_{2}=p_{2,1}+\left(1-p_{2,1}\right) p_{1}$. The ratio $R /(1-p)$ was calculated from Eq. (2) using the $B R F_{\lambda}$ simulated with the stochastic radiative transfer equation.

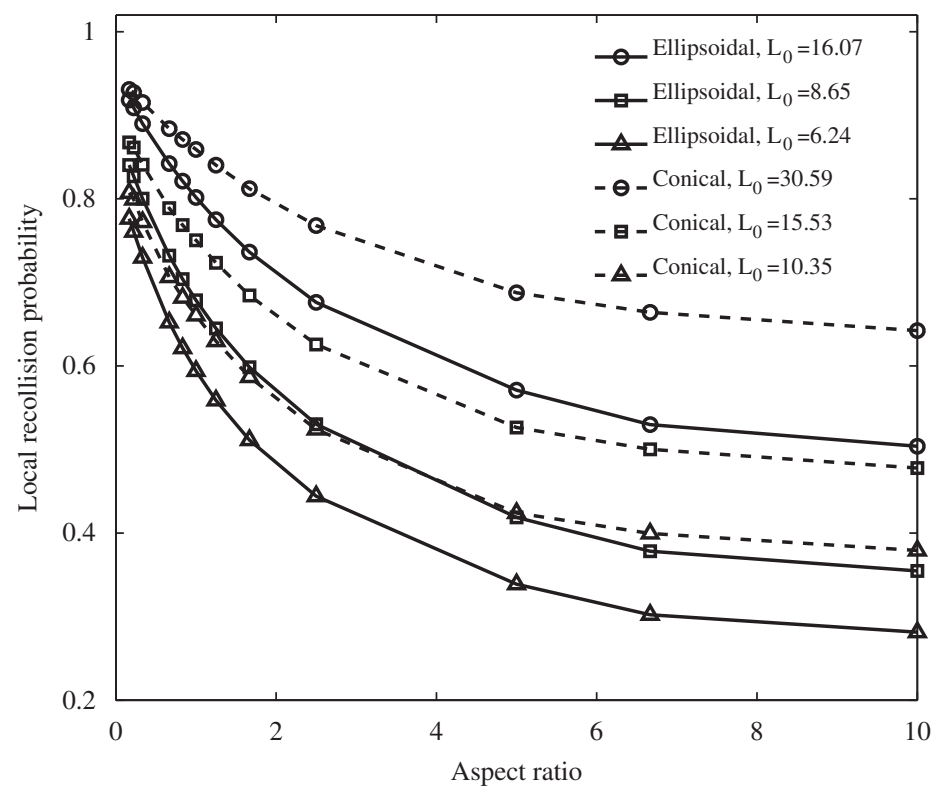

Fig. B2. Probability that a photon scattered by a leaf within a tree crown will interact within the same crown again (local recollision probability $p_{2,1}$ ). Calculations are performed for ellipsoidal and conical tree crowns. Increase in the aspect ratio involves a decrease in crown volume with the tree optical height unaltered. 


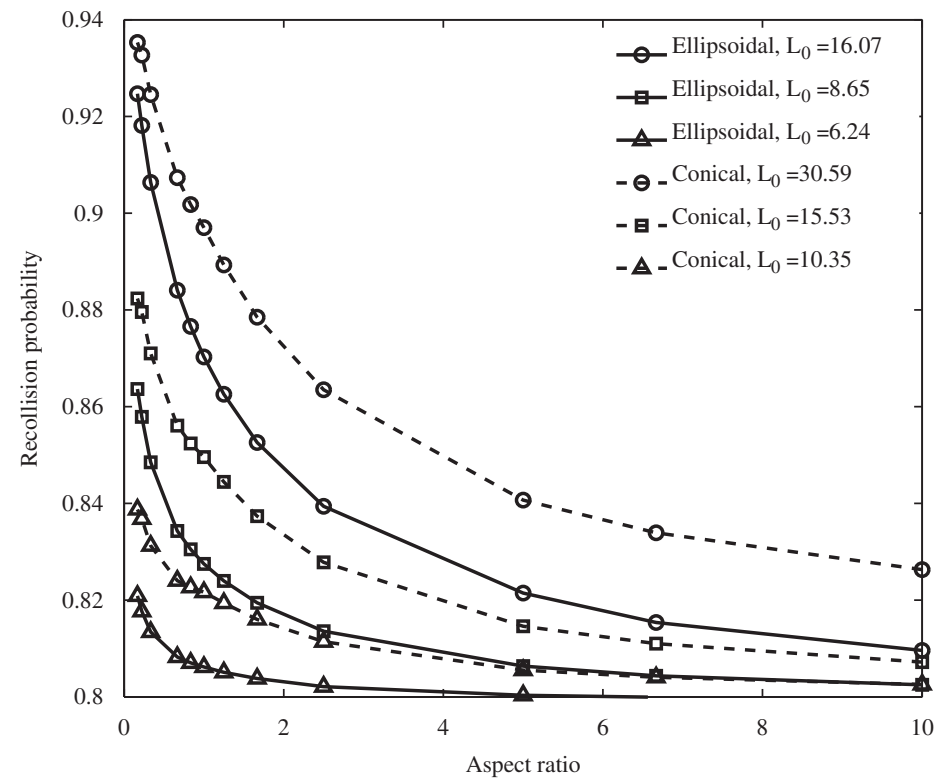

Fig. B3. Recollision probability as a function of the aspect ratio for different values of the ground cover. Calculations are performed for a forest consisting of ellipsoidal and conical trees. Canopy leaf area index, $\mathrm{LAI}=L_{0} \Phi(\mathrm{g})$, is fixed at 4.5.

\section{References}

[1] Myneni RB, Keeling CD, Tucker CJ, Asrar G, Nemani RR. Increased plant growth in the northern high latitudes from 1981 to 1991. Nature 1997;386:698-702.

[2] Nemani RR, Keeling CD, Hashimoto H, Jolly WM, Running SW, Piper SC, et al. Climate driven increases in terrestrial net primary production from 1982 to 1999. Science 2003;300(5625):1560-3.

[3] Hansen J. Tipping point: perspective of a climatologist. In: Woods W, editor. State of the wild 2008-2009: a global portrait of wildlife, wildlands, and oceans. Washington, DC: Wildlife Conservation Society/Island Press; 2008. p. 6-15.

[4] Smith LC, MacDonald GM, Velichko AA, Beilman DW, Borisova OK, Frey KE, et al. Siberian peatlands, a net carbon sink and global methane source since the early Holocene. Science 2004;303:353-6.

[5] JPL. NASA, HyspIRI Whitepaper and workshop report, JPL Publication 2009, 09-19, 2008.

[6] National Research Council. Earth Science and Applications from Space: National Imperatives for the Next Decade and Beyond. Committee on Earth Science and Applications from Space: a community assessment and strategy for the future. Academies Press; 2007.

[7] Zhang Y, Tian Y, Myneni RB, Knyazikhin Y, Woodcock CE. Assessing the information content of multiangle satellite data for mapping biomes. I. Statistical analysis. Remote Sensing Environment 2002;80:418-34.

[8] Dennison PE, Roberts DA. Endmember selection for multiple endmember spectral mixture analysis using endmember average RMSE. Remote Sensing of Environment 2003;87(2-3):123-35.

[9] Dennison PE, Roberts DA. The effects of vegetation phenology on endmember selection and species mapping in Southern California Chaparral. Remote Sensing of Environment 2003:87(2-3):295-309.

[10] Bork EW, West NE, Price KP. Calibration of broad- and narrow-band spectral variables for rangeland cover component quantification. International Journal of Remote Sensing 1999;20:3641-62.

[11] Thenkabail PS, Enclona EA, Ashton MS, Van Der Meer B. Accuracy assessments of hyperspectral waveband performance for vegetation analysis applications. Remote Sensing of Environment 2004;91:354-76.

[12] Ustin SL, Roberts DA, Gamon JA, Asner GP, Green RO. Using imaging spectroscopy to study ecosystem processes and properties. BioScience 2004:54:523-34.

[13] Serrano L, Ustin SL, Roberts DA, Gamon JA, Penuelas J. Deriving water content of chaparral vegetation from AVIRIS data. Remote Sensing of Environment 2002;74(3):570-81.
[14] Fuentes DA, Gamon JA, Cheng Y, Claudio HC, Qiub H-L, Mao Z, et al. Mapping carbon and water vapor fluxes in a chaparral ecosystem using vegetation indices derived from AVIRIS. Remote Sensing of the Environment 2006;103:312-23.

[15] Claudio HC, Gamon JA, Cheng Y, Fuentes D, Rahman AF, Qiu H-L, et al. Monitoring drought effects on vegetation water content and fluxes in chaparral with the $970 \mathrm{~nm}$ water band index. Remote Sensing of Environment 2006;103:304-11.

[16] Wessman CA, Aber JD, Peterson DL, Melillo JM. Remote sensing of canopy chemistry and nitrogen cycling in temperate forest ecosystems. Nature 1988;333:154-6.

[17] Roberts DA, Green RO, Adams JB. Temporal and spatial patterns in vegetation and atmospheric properties from AVIRIS. Remote Sensing of Environment 1997;62:223-40.

[18] Ollinger SV, Smith M-L. Net primary production and canopy nitrogen in a temperate forest landscape: an analysis using imaging spectroscopy, modeling and field data. Ecosystems 2005;8:760-78.

[19] Ollinger SV, Richardson AD, Martin ME, Hollinger DY, Frolking SE, Reich PB, et al. Canopy nitrogen, carbon assimilation and albedo in temperate and boreal forests: functional relations and potential climate feedbacks. Proceedings of the National Academy of Sciences 2008;105(49):19335-40.

[20] Combal B, Baret F, Weiss M, Trubuil A, Mace D, Pragnere A, et al. Retrieval of canopy biophysical variables from bi-directional reflectance using prior information to solve the ill-posed problem. Remote Sensing of Environment 2003;84:1-15.

[21] Knyazikhin Y, Marshak A, Myneni RB. Three-dimensional radiative transfer in vegetation canopies and cloud-vegetation interaction. In: Marshak $A$, Davis $A B$, editors. Three dimensional radiative transfer in the cloudy atmosphere. Berlin: Springer-Verlag; 2005. p. 617-52.

[22] Ganguly S, Schull MA, Samanta A, Shabanov NV, Milesi C, Nemani RR, et al. Generating vegetation leaf area index earth system data record from multiple sensors. Part 1: Theory. Remote Sensing of Environment 2008;112:4333-43.

[23] Knyazikhin Y, Martonchik JV, Myneni RB, Diner DJ, Running SW. Synergistic algorithm for estimating vegetation canopy leaf area index and fraction of absorbed photosynthetically active radiation from MODIS and MISR data. Journal of Geophysical Research 1998;103:32257-74.

[24] Panferov O, Knyazikhin Y, Myneni RB, Szarzynski J, Engwald S, Schnitzler KG, et al. The role of canopy structure in the spectral variation of transmission and absorption of solar radiation in vegetation canopies. Transactions on Geoscience and Remote Sensing 2001;39:241-53. 
[25] Huang D, Knyazikhin Y, Dickinson RE, Rautiainen M, Stenberg P Disney M, et al. Canopy spectral invariants for remote sensing and model applications. Remote Sensing of Environment 2007;106: 106-22.

[26] Knyazikhin Y, Schull M, Xu L. Canopy spectral invariants, Part 1: A new concept in remote sensing of vegetation. Journal of Quantitative Spectroscopy \& Radiative Transfer 2011;112:727-35.

[27] Wang Y, Buermann W, Stenberg P, Voipio P, Smolander H, Häme T, et al. New parameterization of canopy spectral response to incident solar radiation: case study with hyperspectral data from pine dominant forest. Remote Sensing of Environment 2003;85: 304-15.

[28] Mõttus M. Photon recollision probability in discrete crown canopies. Remote Sensing of Environment 2007;110:176-85.

[29] Mõttus M, Stenberg P, Rautiainen M. Photon recollision probability in heterogeneous forest canopies: compatibility with a hybrid GO model. Journal of Geophysical Research 2007;112:D03104, doi:10.1029/2006JD007445.

[30] Schull MA, Ganguly S, Samanta A, Huang D, Shabanov NV, Jenkins JP, et al. Physical interpretation of the correlation between multiangle spectral data and canopy height. Geophysical Research Letters 2007;34:L18405, doi:10.1029/2007GL031143.

[31] Disney M, Lewis P, Quaife T, Nichol C. A spectral invariant approach to modeling canopy and leaf scattering. Proc. The ninth international symposium on physical measurements and signatures in remote sensing (ISPMSRS) 2005; 17-19 October 2005, Beijing, China, Part 1, p. 318-20.

[32] Smolander S, Stenberg P. Simple parameterizations of the radiation budget of uniform broadleaved and coniferous canopies. Remote Sensing of Environment 2005;94:355-63.

[33] Rautiainen M, Mõttus M, Stenberg P. On the relationship of canopy LAI and photon recollision probability in boreal forests. Remote Sensing of Environment 2009;113:458-61.

[34] Rochdi N, Fernandes R, Chelle M. An assessment of needles clumping within shoots when modeling radiative transfer within homogeneous canopies. Remote Sensing of Environment 2006;102: 116-34.

[35] Lewis P, Disney M. Spectral invariants and scattering across multiple scales from within-leaf to canopy. Remote Sensing of Environment 2007;109:196-206.

[36] Mesarch MA, Walter-Shea EA, Hays CJ. BOREAS TE-12 Leaf Optical Data for SSA Species. Data set. Available on-line [http://www.daac. ornl.gov] from Oak Ridge National Laboratory Distributed Active Archive Center 1998, Oak Ridge, Tennessee, USA. doi:10.3334/ ORNLDAAC/352.

[37] Gates DM, Keegan HJ, Schleter JC, Weidner VR. Spectral properties of plants. Applied Optics 1965;4:11-20.

[38] Green RO, Eastwood ML, Sarture CM, Chrien TG, Aronsson M, Chippendale $\mathrm{BJ}$, et al. Imaging spectroscopy and the airborne visible infrared imaging spectrometer (AVIRIS). Remote Sensing of Environment 1998;65:227-48.

[39] Adler-Golden SM, Matthew MW, Bernstein LS, Levine RY, Berk A, Richtsmeier SC, et al. Atmospheric correction for short-wave spectral imagery based on MODTRAN4. SPIE Proceedings, Imaging Spectrometry 1999;3753:61-9.
[40] Gopal S, Woodcock C. Theory and methods for accuracy assessment of thematic maps using fuzzy sets. Photogrammetric Engineering and Remote Sensing 1994;60(2):181-8.

[41] Gould E, Foster D. Vegetation Inventory (3000 acres). Harvard Forest Data Archive 2000, HF037, 1986.

[42] Hall B. Harvard Forest Properties GIS. Harvard Forest Data Archive, HF110, 2005.

[43] LI-COR. In: LI-1800-12 Integrating sphere instruction manual, Pub. No. 8305-0034. Lincoln, NE: LI-COR, Inc.; 1983.

[44] Daughtry CST, Biehl LL, Ranson KJ. A new technique to measure the spectral properties of conifer needles. Remote Sensing of Environment 1989;27:81-91.

[45] Oker-Blom P, Smolander $H$. The ratio of shoot silhouette area to total needle area in Scots pine. Forest Science 1988;34:894-906.

[46] Stenberg P, Kangas T, Smolander H, Linder S. Shoot structure, canopy openness, and light interception in Norway spruce. Plant, Cell and Environment 1999;22:1133-42.

[47] Stenberg P, Palmroth S, Bond BJ, Sprugel DG, Smolander H. Shoot structure and photosynthetic efficiency along the light gradient in a Scots pine canopy. Tree Physiology 2001;21:805-14.

[48] Smolander S, Stenberg P. A method to account for shoot scale clumping in coniferous canopy reflectance models. Remote Sensing of Environment 2003;88:363-73.

[49] Stoyan D, Kendall SW, Mecke J. Stochastic geometry and its application. New York: John Wiley \& Sons; 1995.

[50] Huang D, Knyazikhin Y, Yang W, Deering DW, Stenberg P, Shabanov $\mathrm{NV}$, et al. Stochastic transport theory for investigating the threedimensional canopy structure from space measurements. Remote Sensing of Environment 2008;112:35-50.

[51] Ross J. The radiation regime and architecture of plant stands. Norwell, MA: Dr. W. Junk; 1981.

[52] Vainikko GM. Transfer approach to the mean intensity of radiation in non-continuous clouds. Trudy MGK SSSR, Meteorological Investigations 1973;21:28-37.

[53] Titov GA. Statistical description of radiation transfer in clouds Journal of the Atmospheric Sciences 1990;47:24-38.

[54] Shabanov NV, Knyazikhin Y, Baret F, Myneni RB. Stochastic modeling of radiation regime in discontinuous vegetation canopies. Remote Sensing of Environment 2000;74(1):125-44.

\section{WWW sites}

[WWW1] Ameriflux 〈http://public.ornl.gov/ameriflux $>$.

[WWW2] USDA Forest Service, Northern Research Station $<$ http://www. fs.fed.us/ne/durham/4155/bartlett.htm $>$.

[WWW3] Airborne Visible/Infrared Imaging Spectrometer (AVIRIS) Homepage 〈http://aviris.jpl nasa gov >

[WWW4] NH GRANIT 〈www.granit.sr.unh.edu $\rangle$.

[WWW5] Distributed Active Archive Center, Oak Ridge National Laboratory 〈http://daac.ornl.gov/BOREAS/boreas_home_page.html $\rangle$. 